\title{
Integrating Research and Education with Public Outreach at Coastal Laboratories
}

John D. Milliman

Virginia Institute of Marine Science

Follow this and additional works at: https://scholarworks.wm.edu/vimsarticles

Part of the Higher Education Commons

\section{Recommended Citation}

Milliman, John D., "Integrating Research and Education with Public Outreach at Coastal Laboratories" (1996). VIMS Articles. 1699.

https://scholarworks.wm.edu/vimsarticles/1699

This Article is brought to you for free and open access by W\&M ScholarWorks. It has been accepted for inclusion in VIMS Articles by an authorized administrator of W\&M ScholarWorks. For more information, please contact scholarworks@wm.edu. 


\title{
Integrating Research and Education with Public Outreach at Coastal Laboratories
}

\author{
JOHN D. MILLIMAN \\ College of Marine Science, Virginia Institute of Marine Science, College of William and Mary, \\ Gloucester Point, Virginia 23062
}

\begin{abstract}
Coastal marine and Great Lakes laboratories increasingly are asked to provide both advisory and educational outreach to the general (and often specific) public. To facilitate this interchange, basic and applied research must be more integrated with advisory services, with care taken to present facts and concepts, not opinions or advocacy. Moreover, outreach efforts should be proactive, not reactive. With the rapid expansion of telecommunications, such as electronic mail and teleconferencing, outreach can optimize the links between education and research.

Public outreach also gives graduate students an opportunity to utilize practical applications and interpretations of marine science, thus providing valuable experience that can help in obtaining future jobs. More problematic is how outreach activities can be evaluated in an annual or promotion review of a faculty member; particular care must be taken not confuse outreach with scholarship, or sacrifice intellectual rigor, in such evaluations.
\end{abstract}

\section{Introduction}

Marine laboratories and departments in recent years have been asked to provide the public sector with an ever increasing amount of advice and knowledge about the marine environment. In part this reflects an increased public awareness of the environment and society's interdependence upon it. At the same time, marine laboratories have more information to share, because the opportunities for coastal research have expanded in recent years.

This paper was originally presented at a workshop titled Roles of Coastal Laboratories in the Implementation of the Nation's Emerging Priorities for Research in the Coastal Zone. The workshop, organized by the National Association of Marine Laboratories, was held in Sarasota, Florida, from 24 to 27 October 1995.
The end of the Cold War and the subsequent diminished Soviet military threat meant a major shift in defenserelated research (see Wunsch, 1993, for an insightful discussion). No longer do our immediate security threats come from countries with formidable naval fleets; rather, future conflicts may well involve coastal operationsmine warfare, landing craft operations, and subsequent impacts on harbors and coastal waters. As a result, much of the national defense research has shifted from deepwater acoustics, water circulation, and bottom morphology to coastal problems such as shelf dynamics. At the same time, coastal research programs in other agencies have increased substantially: e.g., Coastal Ocean Program (CoOP), Land-Margin Ecosystem Research (LMER), Shelf Edge Exchange Processes (SEEP), etc. Thus, coincident with an increased public concern for the coastal ocean, researchers and educators are shifting their attention coastward.

This paper addresses the role of coastal marine laboratories in public outreach activities. What types of activities are involved, how can they be optimized, and how should we evaluate faculty activities in outreach programs? I prescribe no solutions, but I try to define questions that each coastal laboratory should consider.

\section{Public Outreach and New Roles for Coastal Laboratories}

By its very name, outreach defines the proffering of experience or advice to the general public from an expert, in this case the research marine scientist or extension agent. Implicit in the word outreach is that it most often is proactive, but my colleague Bill DuPaul has found that only about 60 percent of the advisory work at the Virginia Institute of Marine Science (VIMS) is planned; the rest is reactive to unforeseen problems and opportunities. Out- 
reach also should be scientific in basis and unbiased in approach. Moreover, by its very nature and clientele, public outreach generally addresses short-term, local problems rather than longer term, global problems. Thus, beach erosion and aquaculture are more likely outreach concerns than is global climate change, although global problems may be intimately involved in local problems, such as the role of global climate change in the local rise of sea level.

As I define the term, outreach encompasses two distinct types of activities. Although both involve the transfer of scientific or technological knowledge, advisory services can lead to a practical or economic outcome, whereas educational outreach most often involves information transfer for its own sake. Advisory services should transfer knowledge in a form useful to people, encourage appropriate adoption of this knowledge, and stimulate others to carry out research to solve coastal problems (NOAA, 1978). Examples of advisory services are numeroushelping in fishing trawl design, advice on aquaculture, conservation assistance, local or state planning, etc., but most are aimed at encouraging a change in the client's method of operation. A proposed harbor development, for example, might be reconsidered if it is concluded that dredging will affect local fisheries; the mesh size of trawl nets may be increased if this increases the stock of fecund females, etc.

Educational outreach can include teaching students in kindergarten through high school or teaching their teachcrs, many of whom either have had no formal scicnce training themselves or whose scientific education is dated. Special audiences also can use educational outreach, e.g., clubs, Elderhostel. Finally, educational outreach can include answering ad hoc questions by the curious public"I found this strange shell today. . ."

In the early years of U.S. higher education, most college and university faculty members were primarily concerned with teaching, not research. But the passage of the first and second Morrill Land-Grant Acts in 1862 and 1890, which led to the establishment and funding of Land-Grant colleges, raised the expectation that faculty at these institutions would also participate in extension services, that is, provide service to their constituents. By the turn of the century, basic research at many universities was being emphasized, often at the expense of teaching, and public service as a normal faculty activity was de-emphasized (Boyer, 1990). It is only recently that such concepts as "service", "outreach" and "extension and advisory services" have been championed once again, perhaps in part because of the public's increased concern about how funds are spent.

To most of us this renewed emphasis on outreach seems to have occurred almost overnight. For instance, could the following words have been accepted and incorporated into college and university strategic plans even 20 years ago?

Goal: To make public service a more visible part of the curriculum.

Goal: To increase student participation in public service activities.

Goal: To increase the visibility and influence of public service . . . and extend the reach of the College's public service activities.

(College of William and Mary, 1995)

or:

Advisory service is recognized as a fundamental feature . . . that is dependent upon, integrated with, and supported by the contribution that institutional research and scholarship makes to its content, quality and value. Advisory services should strive to be proactive and anticipatory . . . Advisory service is also of considerable value to the graduate program, where it offers unique educational opportunities.

(VIMS, 1995)

In contrast to the last century, when many practical questions revolved around farming, extension services provided by colleges and universities now encompass a far greater range of needs and interests. As the number of coastal inhabitants increases, for instance, it is not surprising that there is a corresponding increased interest in water and how mankind lives with it.

\section{Advisory Services-Linking Basic and Applied Research}

A rather simple truism often overlooked by researchers and managers is that most good basic research has practical application, and, conversely, effective applied research necessitates a solid grounding in basic research; that is, applied research can lead to new understandings of basic relationships. A clear example is coastal and estuarine research in which there is a close correlation between scientific problems and management concerns, as seen in a list of scientific research priorities in future coastal ecosystem research (National Research Council, 1994):

- Develop indicators of biological status and processes that reflect ecosystem health and integrity;

- Define better the relationship between physical phenomena and ecosystem structure and function, and utilize in situ observation systems to provide better insights into ecosystem behavior on various time and space scales;

- Understand better the interactions and linkages between atmosphere, watershed and coastal ecosystems, 
and the effects of modifications to land-use and water flow upon transformations to the watershed and coastal habitat;

- Use research, modeling, and monitoring to support effective habitat restoration or rehabilitation.

In each task one recognizes immediate practical problems that correlate with scientific problems. Said another way, can one imagine effective management of an estuary or coastal area without a basic understanding of these scientific phenomena?

As with land-grant universities, much of the ability of marine laboratories to pursue applied research depends on federal funding, often from the National Sea Grant College Program. However, the Department of Commerce (DOC), the National Oceanic and Atmospheric Administration (NOAA) and its agency, Sea Grant, all face increasingly uncertain futures. In recent months DOC and NOAA have been threatened with elimination by various House and Senate committees. Sea Grant's budget always seems to be at the edge of drastic reduction, and the program's survival (with increased funding) is ample evidence of its success. But while Sea Grant Marine Advisory Service programs have continued to grow, most of that growth has come from matching funds $(27 \%$ increase between 1984-89) rather than federal Sea Grant funding (2\% for the same period) (UNC, 1992). Moreover, most researchers often need significantly more money than the Sea Grant budget can provide, and Sea Grant proposal review often is politicized. These problems can drive good researchers to other avenues of funding, one result being that advisory service may become a casualty.

\section{What is the client base for advisory services?}

In coastal work, the clientele includes coastal planners (including port development and marine transportation), the food industry (fishermen, aquaculture, and processing), non-living resources (such as recreation and mining), conservation (including solid waste disposal and coastal erosion), as well as persons concerned with such diverse topics as exotic and endangered species (NOAA, 1978; National Sea Grant Program, 1991). Clearly the types of outreach and advisory activities depend greatly on the institution involved. A large private lab, for instance, may have no local or state constituency upon which it can rely for some of its financial support. In contrast, many statesupported laboratories may include advisory activities in their formal mandates.

The scientist's audience often is defincd by the source of his or her funding. Should a scientist relying solely on NSF and ONR grants necessarily be expected to respond as quickly to a local outreach request as a scientist funded by the state? In the latter case, the scientist is responding to his "funding agency"; in the former case, the scientist's constituency is different, although an NSF-funded scientist is expected to help in proposal reviews and perhaps participate in NSF review panels. A somewhat more subtle problem may arise at a university where a major benefactor may expect (and receive) a faster and more thorough response than someone who has no such university connection.

Many state-funded coastal laboratories have advisory services that are closely analogous to agricultural extension services at Land-Grant universities. Those supplying information may be faculty members or extension agents, often with long-term relationships with specific client groups. Advice can be given to for-profit operations, such as fishermen and aquaculture growers, or to policy makers and implementers, such as planning boards, state or local agencies, and legislative bodies.

Many forces that influence policy decisions are not based on technical facts as scientists might construe them. While it is the responsibility of the scientist to offer the best possible advice, the scientist also must realize that the politician must pay heed to his or her constituency. Said another way, the ultimate decision maker needs to listen to many, but may follow advice based on non-scientific factors, such as economics and politics. A fisheries scientist might conclude that a certain species is in danger of being overfished. He recommends a moratorium, but the moratorium may mean that fishermen will be financially impacted. Hence the moratorium is not implemented.

To be most effective, advisors must be viewed as nonadvocates-they impact knowledge, not opinions (NOAA, 1978). If perceived as representing an unbiased viewpoint, one's perspective or advice may be followed more readily than if the decision-maker views the advice as coming from an advocate. In other words, advisory service should lead to informed decision making.

\section{Optimizing advisory service delivery}

So far, I have discussed mostly advisory services in which the client requests help, either directly or indirectly. But the conveyance of information also can be initiated by the scientist. This goes beyond educational outreach, which is discussed in the following sections, for it deals with how the public receives, understands and relates to research programs at marine laboratories. A sound outreach effort necessitates a logical structure and flow diagram, one example of which is seen in Figure 1. But the linkagc between the provider and the client often requires a facilitator-individual scientists cannot be expected to field any and all questions, at least not effectively.

At many laboratories, calls of interest or questions are answered initially by the switchboard operator, and therefore the call may not be transferred to the most appropriate 


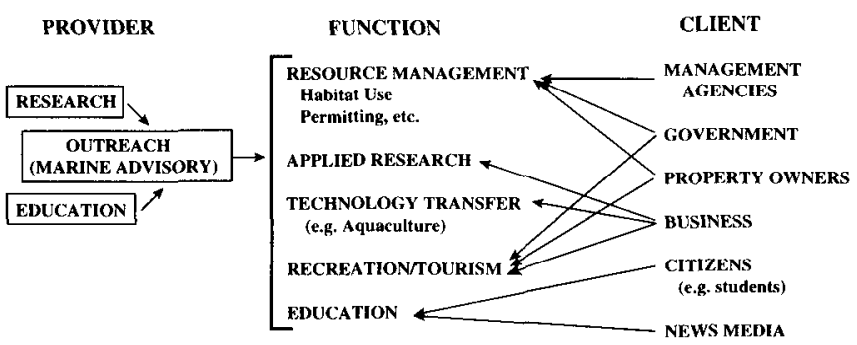

Figure 1. The outreach and marine advisory office at a marine laboratory can provide the vital link between the outreach and educational activities and the client who requests these services. The actual provider, of course, depends on the function required as well as the particular client.

staff member. A more logical (if expensive) way is to have a public information office that is sufficiently linked to the research activities of the laboratory so that it can forward any question to the proper person or office immediately; callers do not like to be referred to a string of offices, particularly if none has answered the request.

Once a request is received and the information provider is assigned, the method and time of response should be identified, so that conflicting messages are avoided. Can the question be handled simply over the phone (e.g., "That dead mass on your front lawn, Madame, is probably a horseshoe crab torn up during the last storm.") or does it require a site visit or time in the library or laboratory? Will it necessitate a simple oral report, a written report, or an appearance at one or more hearings? As Healy and Hennessey (1994) point out, all too often scientists play only episodic roles in resource management science, whereas a more effective method is to have science involved throughout the management process. Unfortunately, the most effective advice may require a great deal more time (i.e., becoming proaclive rather than reactive) than many busy scientists are willing to spend.

It almost goes without saying, but the advice should be given in terms that are easily comprehended by the layman. Even the simplest scientific concepts, however, can prove daunting to the lay person, particularly if the science answer is laced with jargon. Providing incredible insights and sage advice do little good if the user can't understand what is being said.

Inherent in advising and extension service, of course, is the follow-up. What was the outcome of your advice? Was the client's ultimate action successful? Is further work anticipated, and (less altruistically) might this work lead to research opportunities for the scientist or the laboratory?

\section{Working with the media}

The fastest way to reach the public is through the news media. Many marine laboratories have a public infor- mation officer through whom media requests for information or interviews can filter. But whether buffered by an information office or not, most scientists have been interviewed by a reporter whose published article misconveyed the scientist's research or message. Where the news is not "fast-breaking," the sympathetic reporter might allow the scientist to read a draft of the article for technical comments. But where an important story cannot wait, the scientist must present the clearest account to the reporter, knowing that the reporter may have little understanding of the actual underlying science.

Institutions can have media open houses or workshops, where media representatives learn about the activities of the marine laboratory in a more informal manner. The Marine Biological Laboratory in Woods Holc runs a Science Writing Fellowship Program each summer. Alternativcly, scientists can learn how to communicate more effectively with the news media, and a number of scientific organizations have begun to sponsor media and communications programs. The 1996 Ocean Sciences Meeting in San Diego, for instance, offered a short course in communicating with the media, which included practice interviews in which the scientist was questioned by a mock reporter. One piece of advice given in the article announcing this short course (EOS, 1996, v. 77, p. 20) is that the scientist should not feel compelled to supply an immediate answer to all questions; taking an hour or so to prepare an answer is usually okay.

One can, of course, always write one's own article. Semipopular magazines provide one avenue, the best example being Woods Hole Oceanographic Institution's Oceanus, which, for many years, has provided the educated laypublic with clear and concise ideas of the marine environment and how scientists study it. Recently, however, Oceanus's focus has been redirected to concentrate on the scientific research conducted at WHOI.

With the recent explosion in electronic communications, the scientist now can be as close to the public and the media as his or her PC keyboard. One can hold teleconferences at which questions and answers can be immediately communicated. Electronic mail allows one to answer questions and requests in the leisure of one's office, and features like the Internet and World Wide Web provide public access to general information about the institution's general programs as well as recent scientific projects and results. This increased communication along the "Information Highway" can greatly enhance public access as wcll as facilitate rapid feedback. As both the need to publicize one's research and the access to rapid electronic communications increase, however, one could be tempted to confuse the media with peer-reviewed literature. Announcing one's results before they are critically reviewed by peers can have disastrous impact on the credibility of both the scientist and his or her institute. 


\section{Educational Outreach}

As science becomes more complex and difficult to comprehend, the need to educate the public actually increases. Science and engineering were once among the most respected professions in the United States. Our ability to improve our lives as well as achieve economic superiority over other nations depended on our scientific efforts. In recent years, however, the public image of science and scientists has diminished, and often we and our science are misunderstood or ignored altogether. Consider, for example, that one-quarter of Americans think that the Sun revolves around the earth, and nearly half of us do not believe in evolution (Levine, 1990). In large part this inability to comprehend science is because it is based upon additive experience and because it often involves mathematics (Wolpert, 1993), which is a particularly troublesome area for many Americans.

Coupled with poor scientific literacy is the increased need to communicate environmental science to the public. There are two clear reasons for this, one pragmatic and one more idealistic. The pragmatic reason is fairly obvious-the public ultimately pays for much of our research. They are our patrons, as it were. If we cannot communicate effectively to our patrons exactly what we do, we run the risk of losing their support. At the same time, there are important concepts, such as global warming, that we need to communicate to the general public. When a congressman states (as one did in 1995) that global warming is a myth and that the ozone hole is not expanding, does that not partly reflect our inability to present facts in a comprehensible manner? Should we not assume some responsibility for such a lack of comprehension?

On the more altruistic side, environmental science is probably the most practical way of teaching science. While radiation energy, wave theory, and biochemistry are concepts and fields that can confuse or bore the public, the coastal environment involves concepts that can be put into the context of the environment around them. Tides, waves, temperature, geology, and biology all become more easy to comprehend when the student can relate these concepts to something he or she can see or touch. What is more, the student immediately can see the practical application of such science; for instance, understanding the forces and impact of coastal erosion by seeing undercut houses falling into the sea.

Thus an appreciation for both science (in general) and the environment can be gained by exposure to coastal marine science, no matter if the classroom is a pond, an estuary, or the coast. But scientific education goes far beyond simply instilling an understanding of the environment and the processes that affect it. As Rutherford and Ahlgren (1990) point out, students also can learn the concepts of the working hypothesis, patterns of change, con- stancy, as well as mathematics and statistics. The trick, of course, is to make the exposure memorable, preferably one in which the student participates. Practical experience is often best. Learning about the biology of a mollusc from a textbook or a computer is probably less effective than actually holding a scallop in the hand, looking at its parts under a microscope, and studying its behavior in an aquarium.

A few years ago members of the Estuarine Research Federation and the National Marine Educators Association defined the following as the five most important concepts of estuarine education (after Spence et al., 1990):

- mass balance of materials in estuaries with regard to both external and internal sources;

- watershed development and its consequences;

- estuaries as nurseries and spawning grounds;

- hydrodynamics of estuaries, particularly with respect to fresh- and salt-water exchanges; and

- physical-chemical-biological rclationships in estuaries.

Note that each concept involves scientific principles that ultimately have practical implications and that these concepts do not differ greatly from those stated by the NRC (1994) (see above).

The goal in educational outreach should be to educate the general public, not to nurture future oceanographers and marine scientists. Some of the more motivated students might go on to major in science in college, perhaps even marine science, but the vast majority will ultimately benefit by becoming part of the educated public. Increasingly, educators are learning that this process cannot begin too early. Middle school students can understand science more easily if they have been exposed to interesting and comprehensible concepts in elementary school. Waiting until high school is probably too late for most students.

The number of $\mathrm{k}-12$ outreach programs is increasing steadily. The North Carolina Museum of Life and Science, for instance, has issued a number of pamphlets that address "Sharing Science with Children," one dealing with the linking of scientists and engineers with students, and another with a survival guide for scientists and engineers. Our "Bay Team" program at the College of William and Mary is targeted at educating thousands of Virginia students annually. Even NOAA has directed considerable effort to educational outreach by its scientists and engineers (Baker $e t$ al., 1993).

In some ways, educational outreach becomes more problematic when it involvcs adult education. Take, for example, primary school teachers who need a primer course in marine science that can be used for graduate credits required to maintain their teaching accreditation. One probably cannot teach these teachers a graduate-level course in marine science, some of whom probably never 
took a science course in college; nor will many faculty members volunteer to teach a less challenging course. Even if the course can be identified and an instructor chosen, how can graduate credits be justified?

On the other hand, outreach for the general public can be mutually educational for both the "class" and the "teacher," particularly if the outreach activity leads to a future research or funding opportunity. The outreach activity may be as simple as a periodic open house or as detailed as a workshop for legislators. As mentioned above, periodic open houses for the news media might be particularly useful, if not totally altruistic. As S. E. Cozzens (unpub. manuscript) states, "The sign of success is how broad a set of community leaders and citizens would be willing to testify convincingly on behalf of the university at state budget hearings, as well as the level of constituent compliments state legislators receive on the state's higher educational services."

In setting up or expanding such educational outreach programs, of course, one continually needs to ask many of the same basic management questions asked with respect to advisory services: What is the target group, who is the teacher, what is the duration of the event, what is the minimum, optimum, and maximum number of "students" we can serve, and how can we evaluate our impact on these students? Are there ways in which the educational outreach can be streamlined by using electronic technology, or does this simply detract from personal contact? Unless educational outreach is approached in a businesslike manner, it runs the risk of becoming an almost endless time-sink for faculty and staff, one that could disrupt the laboratory's other activities.

As for marine advisory services, one solution is to designate one or more persons specifically trained in educational outreach. This, however, might consume funds that could be used in other ways. An active docent program is an alternative solution that could ease the need for hands-on involvement by laboratory personnel.

\section{Graduate Education and Public Outreach}

Between the 1960s and the 1980s many students graduating with PhDs in the marine sciences were almost assured jobs in research and academia, initially in hardmoney positions as colleges and universities began adding marine science to their curricula, and then in soft-money positions as new teaching opportunities decreased and research opportunities expanded. As recently as a few years ago, NSF talked about the need for a future generation of scientists both to staff new positions and to replace older scientists as they retire.

As we now know, the explosive demand for scientists in academia has not matcrialized. Nationally, more than half of the graduates with PhDs find work in non-academic fields (NAS, 1995), and in marine sciences this fraction may be greater. Data for U.S. marine laboratories are incomplete, but between 1991 and 1993 the number of academic faculty at the $\mathrm{JOI}+5$ oceanographic institutions (Joint Oceanographic Institutions-defined as those schools and institutions with open-ocean research capabilities) remained essentially constant (Nowell, 1993). In 1993, moreover, only one third of the JOI+ 5 faculty were older than 50 and less than 10 percent older than 60 , meaning that it might be at least 10 years before there is a significant number of faculty openings. Increasingly, therefore, we must look to other non-academic positions for our graduate students, not only those with masters degrees but also those with doctorates. One path, of course, is post-doctoral fellowships and non-tenurable faculty positions; but post-doctoral positions provide only a few years of respite from the real world, and surviving on soft money is an increasingly perilous existence in the flatbudget world of marine research (Wunsch, 1993).

The basic goal for all educators is to prepare students with optimal marketable skills, and successful marketing depends on considering new areas of employment. For marine scientists this means that applied research and public outreach must be considered viable alternatives to university teaching and research. Whether this involves education at the lower levels (e.g., junior colleges or secondary schools), advisory work or joining profit-seeking organizations, the emerging markets in marine science appear to be in non-traditional areas.

This change in career opportunities in marine science is reflected in student interest in our graduate program at William and Mary. Between 1988 and 1994 applications increased 400 percent, and interest in management fields, such as environmental science and resource management, increased at an even greater rate. In comparison, between 1988 and 1993, applications to the JOI +5 schools increased by only about 60 percent (Nowell, 1993).

With the job market evolving into non-academic areas, graduate students can profit greatly from actively participating in public outreach programs. Solving concrete, real-world problems and needs can yield valuable experience that might lead to increased employment options. Working with advisory services, for example, can illustrate many of the problems that relate scientific knowledge to management issues, whereas education outreach can demonstrate effective ways to market scientific ideas to a non-scientific public.

Not only do we need to make outreach and advisory options more accessible to our graduate students, we also need to be more proactive by offering a wider variety of non-traditional graduate (and undergraduate) courses. As recently as a few years ago, graduate students at most schools were urged to take only basic science courses. The reality of today and probably for the foreseeable future, 
however, is that students, particularly those interested in coastal environments, will need training in managerial skills, including courses in business administration, economics, and law. My friend John Farrington tells of several physical oceanography graduate students in the MITWHOI joint program who recently took a course in industrial marketing, something that probably would not have happened a few years ago. Interestingly, the students requested the course-not their advisors. As pointed out by the National Academy of Sciences (1995), however, offering a greater range of academic options should not mean that other necessary courses are dropped or that the time to completion of degree is compromised.

\section{Faculty Participation and Evaluation}

As Land-Grant colleges and universities explore ways to increase their outreach to external constituencies, some incentives are needed for those faculty involved in outreach activities. A NASULGC (National Association of State Universities and Land-Grant Colleges) Newsline article (July 1994, p. 6-7) outlines the steps being taken by four universities (Clemson, Minnesota, Oregon State and Michigan State):

-Create incentives to encourage faculty participation in outreach;

-All extension faculty should be affiliated with an academic home (Oregon State);

-Student participation in research or outreach will become a degree requirement (Clemson).

Sea Grant Marine Advisory Services (SGMAS) often include extension agents whose faces and names are unfamiliar to the academic or research faculty. SGMAS programs always reside within universities, but rarely are they part of important decision-making processes, and thus may be considered peripheral (UNC, 1992). As a result, professional advancement and career ladders for SGMAS personnel can be ill-defined or non-existent (UNC, 1992). To remedy these problems, the UNC report makes the following recommendations:

-Outreach programs should be identified as an integral activity of the university;

- Administrative and programmatic decisions regarding SGMAS activities should be integrated within the university system to facilitate the setting of policies, budgets and initiatives;

-Agents and specialists should have clearly defined professional advancement opportunities;

-Staff with advanced degrees should have the opportunity to obtain departmental affiliation and gain advancement within that department, including tenure.
The VIMS (1995) strategic plan states one goal as being, "(To) increase faculty awareness of educational outreach as an important area for faculty participation and service. Provide incentives for participation." But how outreach participation should be evaluated is open to debate. The problem is two-fold: one deals with the standards used in evaluating outreach, the other asks how outreach activity and results can be equated to teaching and research activities. The first problem is an absolute measure; the second is a relative measure. Teaching and research are relatively easy to evaluate: class enrollments, student evaluations, number of papers published, citation index, research grants, etc. But how does one evaluate the impact of teaching estuarine ecology to a middle school class for several hours, days or weeks? Because the rating standards are so qualitative, evaluations by definition will be fuzzy. Some of these problems are discussed in a recent book by Diamond and Adam (1993).

I remember about 20 years ago when a scientist at WHOI was warned to be less involved in the graduate education program and more involved in research; the scientist subsequently left WHOI. While this might not happen today, one wonders how various marine laboratories would respond to a faculty member who spends one day per week working with $\mathrm{K}-12$ students or lecturing at retirement homes. Would the scientist be expected to do this in addition to normal office hours? Even if his involvement were condoned or even applauded, how would it be received by an external tenure review of that faculty member?

The traditional measure of a faculty member is the number of courses taught, students mentored, and (often primarily) peer-reviewed papers and citation indices. Not only are these considered accurate measures of productivity and impact, but they are relatively easy to quantify. It is much more difficult to evaluate the faculty member who spends considerable effort in outreach. How does one judge outreach effort and its impact? What are the terms of measure, can they be quantified, and how does one compare this against the more common measures of performance?

The problem bccomes more complicated in a department containing faculty members who are essentially extension agents. In one version of a perfect world, all faculty members would participate equally in teaching, research, and outreach, and evaluations could be based on some integrated sum of the total effort. But in the real world, some faculty emphasize teaching and some research. While this division of labor nearly always creates controversy, most departments recognize the reality and (often) advantages of diverse activities. But the problems increase when one adds in extension service, which many still do not view as an academic activity, and certainly not one easily evaluated.

One obvious question is whether extension agents should have faculty appointments and be evaluated by 
the same standards applied to more traditional faculty members? At VIMS, where special emphasis is placed on outreach, there are two nested faculties. All faculty are members of the VIMS faculty, but only those directly involved in the educational program are members of the School of Marine Science (SMS) faculty. Appointment to the College of William and Mary, as well as tenure, resides within VIMS, and one can move on or off membership in SMS without losing the VIMS affiliation. As a result, many of our faculty more involved in advisory work and outreach belong within VIMS, but not SMS. While this may seem like a reasonable way to incorporate extension faculty into an academic department or school, the system is not without flaws. Membership within SMS is considered by most VIMS faculty as having a more prestigious status, leading some faculty involved primarily in extension work to seek membership in SMS. Yet if their annual teaching and research activities don't match SMS expectations, they can be removed from SMS.

Whatever the method of evaluation, no faculty can be evaluated fairly without some quantitative measure of his or her research effort and its net effect. The VIMS Strategic Plan (1995) states it rather simply, "(Advisory service) is . . . an integral part of overall scholarly expectations of faculty along with teaching and research, but it is not a substitute for scholarship" (Emphasis is mine). In other words, one cannot hide behind outreach. Extension agents, in fact, may need to spend more effort in becoming acquainted with new concepts and developments that may affect their areas of specialty. From this, scholarly research may ensue.

\section{Conclusion}

Marine science research and education appear to place increasing emphasis on nearshore processes and problems. At the same time, and almost certainly in large part because of this new emphasis, the need and demand for public outreach also are increasing. Coastal laboratories have an obligation to enhance their outreach efforts so that their research and educational activities are more directly applied to applied research and societal needs. The problems raised by this shift in direction, however, are not inconsequential; for example, laboratory organization, the management of outreach requests, gauging feedback, evaluating faculty performance, and so forth. But the payback in terms of increased research opportunities, increased job opportunities for graduate students, and the altruistic reward of communicating useful knowledge cannot be minimized.

\section{Acknowledgments}

I thank the NAML Steering Community for the opportunity to participate in its Sarasota workshop and to prepare a paper that allowed me to synthesize some of my thoughts about an increasingly critical subject. Marine Advisory Services and Educational Outreach at VIMS are directed by Bill DuPaul and Lee Larkin, respectively, and many of my statements reflect more their long-term practice than my newly found knowledge. I thank both of them, as well as Bob Byrne and Don Wright, also of VIMS, for their helpful comments. Jeff Bryant, Monterey Bay Aquarium, supplied almost instant notes from the discussion at the Sarasota NAML meeting, which aided in the final revision. I thank Tom Malone for the invitation to prepare this paper and for his help with an earlier version of this paper. Two anonymous reviewers helped greatly with their editorial comments on the final manuscript. Michael Greenberg was particularly helpful with his philosophical insights to parts of the paper and his editorial comments.

\section{Literature Cited}

Baker, D. J., D. K. Hall, D. H. Josephson, and K. D. Sullivan. 1993. NOAA 1995-2005 strategic plan. (draft, July 1993).

Boyer, E. L. 1990. Scholarship Reconsidered: Priorities For the Professoriate. Carnegie Found. Adv. Teaching, Princeton, NJ.

College of William and Mary. 1995. Into the Fourth Century. A Plan for the Future of the College of William and Mary. $35 \mathrm{pp}$.

Cozzens, S. E. Changing expectations and assessment of the research university. Competiveness in Research: A Review and Assessment. Amer. Assoc. Advancement Sci., Directorate for Science and Policy Programs (27 Jan 1995 Draft).

Diamond, R. M., and B. E. Adam, 1993. Recognizing Faculty Work: Reward Systems for the Year 2000. Jossey-Bass Publ., San Francisco. $125 \mathrm{pp}$.

Healy, M. C., and T. M. Hennessey. 1994. The utilization of scientific information in the management of estuarine ecosystems. Ocean Coast. Management 23: 167-191.

Levine, J. 1990. Scientific literacy. Oceanus 33 (3): 66-73.

National Academy of Sciences. 1995. Reshaping the Graduate Education of Scientists and Engineers. National Academy Press, Washington.

National Research Council. 1994. Priorities of Coastal Ecosystem Science. National Academy Press, Washington. $106 \mathrm{pp}$.

National Sea Grant College Program. 1991. Sea Grant's Marine Advisory Service. Looking into the Future. $12 \mathrm{pp}$.

Nowell, A. 1993. Graduate students in oceanography. Unpubl. report for Ocean Science Educators' Retreat (OSER), Honolulu.

Rutherford, E. J., and A. Ahlgren. 1990. Science for All Americans. Oxford Univ. Press. 246 pp.

Spence, L., N. Armstrong, and M. J. Jones. 1990. Top priorities in estuarine education concepts. Current 10: 28-30.

U.S. National Oceanic and Atmospheric Administration. 1978. Effective Marine Advisory Services. $20 \mathrm{pp}$.

University of North Carolina. 1992. The Nation's Coastal Technology Transfer Program for the 21st Century. Sea Grant College Program, $20 \mathrm{pp}$.

Virginia Institute of Marine Science. 1995. Research, Education and Advisory Service: A Strategic Plan for Restructuring the Virginia Institute of Marine Science, School of Marine Science of the College of William and Mary. Williamsburg, VA.

Wolpert, L. 1993. The Unnatural Nature of Science. Harvard University Press, Cambridge. 191 pp.

Wunsch, C. 1993. Marine sciences in the coming decades. Science 259: 296-297. 